\title{
Research on the Gender Difference in the Language Development of Children
}

\author{
Lina Zhang \\ Teachers' College Shenyang University \\ Shenyang, China
}

\author{
Yanli Cao \\ Changying Kindergarten 96101 Unit the Chinese People”s \\ Liberration Army \\ Shenyang, China
}

\begin{abstract}
The levels of human language development are different. According to the research, it is found that gender difference plays an important role in children's language development. This paper starts from the genders of children uniquely and uses literature method to analyze the factors that affect the development of children's language, summarizes the performance of gender difference in the process of children's language development, and puts forward an effective intervention strategy for the problems and misunderstanding in respect of the impact of gender factor on their language development, so as to reduce the difference of language development and better promote the language development of children. The research value of this paper is to sum up from the literature and to give countermeasures to solve the problems that affect the language development of children because of gender factor, so as to promote the development of intelligence.
\end{abstract}

\section{Keywords - Children; Language; Influential factors}

\section{INTRODUCTION}

Many scholars and preschool teachers at home and abroad are involved in the study of gender difference in the process of children's language development. In Overview of Domestic Yu Yang's Research on Gender Difference, Gengshan Shi, National Research Center of Foreign Language Education, Beijing Foreign Studies University and Shanglian Zhang, School of Foreign Languages, Hebei University of Technology, have introduced and analyzed in the face of the domestic existing research results through the theoretical construction and gender discrimination in language, gender language expression form and gender difference in speech communication and other aspects and have discussed the future development trend. [3] Therefore, this paper has studied the gender difference factor among factors affecting the language development of children and solutions through literature, comprehensive analysis and other methods, and gives some suggestions and advices appropriately, hoping to help the language development of children.

\section{RELATED CONCEPTS AND RESEARCH SIGNIFICANCE}

\section{A. Language}

Language is a unique form of communication. When it acts on the relationship between human and the objective world, it is a tool for understanding things. When it acts on culture, it is the carrier and container of cultural information. [1] The language significance mainly has the following points:

(1) The purpose of language is to express, and we can use language to express our thoughts and ideas, and we can express better by combining with body language.

(2) The significance of language lies in interpersonal communication. Conducting the language dialog with others is a kind of communication

(3) The expression of language requires skill. When we express our language, our meaning can be understood better and faster by other people only by complete, concise and clear expression.

\section{B. Language Development}

Language development is the process of individual learning mother language after birth. Strictly speaking, the development of language begins with the first real word of individual at the age of 1 or so. Therefore, with the emergence of words, the whole process is divided into two stages. Language preparation period, also known as the pre-language period, mainly includes two aspects: language production and language understanding. The period of language development mainly includes the development of syntax, the use and understanding of words, and the development of pragmatic competence.

\section{Gender}

Gender is one of the social categories formed in people at the earliest and used to classify other people. In psychological research, gender is divided into "physiological gender" and "social gender" [1]. The former refers to the differences in the physiological structure and physiological function of male and female, the latter refers to the understanding of the differences between male and female which are formed for social culture, as well as the group characteristics and behavior patterns of male and female. 


\section{INFLUENCING FACTORS OF THE LANGUAGE DEVELOPMENT OF CHILDREN}

\section{A. Environmental Factor}

Environmental factor refer to the environment contacted in the process of children's language development, whether it is kindergarten environment, social environment, family environment and so on. It has a direct relationship with the development of language.

\section{1) Kindergarten Environment}

The material environment and spiritual environment of kindergartens affect the language development of children to a large extent. Bruner believes that children do not learn languages in an isolated environment. He emphasizes the decisive influence of profound social interaction on language, and thinks that teachers should attach importance to creating environment conducive to the language development of children and promote the language development of children in normal communication and conversation with other children. At the same time, good language environment is also an important way to promote the rapid development of children's intelligence quotient. Thus, a good language environment in kindergartens is very important.

\section{2) Family Environment \\ (1) Cultural Level}

Families with low vocational education background and low income are more likely to lack scientific education for children and neglect the language development of children. In their opinions, what is healthy and good life for their children is to have good materials and not to be sick. But they do not know that children will gradually lose the best time to learn language in such a life, which is not conducive to the language development of children.

\section{(2) Family Relationship}

If the relationship between family members is tense, this disharmonious atmosphere will have a negative impact on the children's psychology, the children will feel alone and not be willing to communicate, even never tell their own inner thoughts, so the development of language is more vulnerable to be subject to obstacles.

\section{(3) Upbringing Way}

Spoiling upbringing will enable children to live like parasites. Although this way can reflect the parents' circumspection and care for children, it will also cause children to have no independent self-care ability. In life, children do not have to express anything at all. There will be someone who may prepare everything for them, and the language development of children will be naturally delayed.

\section{B. Physiological Factors}

\section{1) Modern Neurolinguistics}

Modern neurolinguistics reveals that human brain and speech organs are superior to other species in function and structure. Studies have shown that the left hemisphere of the brain is related to language ability, and the left hemisphere is mainly in charge of language. He can distinguish things and say things. The physiological damage of brain and speech organs will directly affect the language function to be performed normally.

\section{2) Physiological Genetic Factor}

Scientific research has shown that children may inherit phonetic organs and nervous structures, and language skills can be inherited through human-specific species properties. The highly developed brain and other organs provide a physiological basis for language production, which also proves that language development is progressive. Children's language ability is a genetic potential to some extent, and its development will be gradually mature with the biological development.

\section{PERFormanCE OF GENDER DifFERENCE IN THE PROCESS OF CHILDREN'S LANGUAGE DEVELOPMENT}

\section{A. Differences in the Phonological Development}

Speech is mainly composed of pitch, length and tone. Boys and girls are different in these aspects.

\section{1) Pitch Difference}

Pitch refers to the level of sound, depending on the frequency of vocal cord vibration when producing sound. Studies have shown that girls generally like to use ultra high pitch and ultra low pitch, and use more types of tunes than boys. And boys generally use medium pitch.

\section{2) Length Difference}

The length is the length of the sound. According to the survey, girls usually have longer voice than boys at normal speed. This is because girls may consider other people's feelings in the process of expressing language, which is an adaptation of psychological activity.

\section{3) Tone Difference}

Tone refers to the sensory characteristics of sound, mainly determined by the shape of the sound, the way of pronunciation and the shape of the resonator. Each person's pronunciation is different from each other in these aspects, so everyone's mood is different. It can be divided into male sound and female sound according to gender. This is due to the physiological factor of male and female organs.

4) Gender Characteristics of Phonological Awareness

There are relatively few studies on whether there is gender difference in children's phonological awareness, so some data have been investigated in the following table: [2]. 


\begin{tabular}{|l|l|l|l|l|l|l|l|l|}
\hline & Gender & $\mathrm{N}$ & $\mathrm{M}(\mathrm{SD})$ & $\mathrm{M} \%$ & MD & df & $\mathrm{t}$ & Sig. \\
\hline & Male & 49 & $55.49(15.87)$ & .72 & & & & \\
\hline Phonological awareness & & & & & -3.43 & 95 & -1.078 & .284 \\
\hline & Female & 48 & $58.92(15.42)$ & .77 & & & & \\
\hline
\end{tabular}

It can be seen from the above table that the overall results of the girls' phonological awareness test is slightly higher than that of the boys $(\mathrm{MD}=$ boys' results - the girls' results $=-3.427)$, and the difference of the tested individuals of the same gender in different ages is larger (the standard deviation of the tested male and female subjects is larger)

A lot of researchers have tested the results. In view of the independent sample $t$, we can see that boys and girls do not have much difference in phonological awareness on the whole, which also shows that boys and girls are almost in the same level of awareness in the phonological development.

5) Age and Gender Interaction Characteristics of Children's Phonological Awareness

Whether the age and gender of children's phonological awareness interact or not, the researchers have made records for the phonological awareness of boys and girls in each age group [2]:

TABLE II ACCURACY AND STANDARD DEVIATION OF TESTED PHONOLOGICAL AWARENESS OF MALE AND FEMALE SUBJECTS IN DIFFERENT AGE GROUPS

\begin{tabular}{|c|c|c|c|c|}
\hline & $\mathrm{N}$ & 4 years old & 5 years old & 6 years old \\
\hline \multicolumn{5}{|l|}{ Male } \\
\hline 49 & $.53(16.72)$ & $.83(6.77)$ & $.84(4.76)$ & \\
\hline Female & 48 & $.58(19.42)$ & $.82(5.71)$ & $.89(3.81)$ \\
\hline
\end{tabular}

Looking at the table, we can see that phonological awareness of boys and girls has improved significantly from small to large classes, and the differences between individuals in the same gender are gradually decreasing.

\section{B. Difference in Vocabulary Development}

Because of different genders, boys and girls also differ in vocabulary. Because male and female are different in their interests, it is different in vocabulary between boys and girls. Usually, girls talk about life - related topics, such as clothes, wear, fairy tales and dolls; boys usually like sports, science fiction, cars, and so on, so some of the words about their preferred things may appear in their languages. Secondly, girls prefer to express feelings with interjection or modal particle more than boys, and girls like to use interjection to express surprise, shock, happiness, sadness and so on, and boys like to use modal particle to express anger and dissatisfaction. Finally, most of the modal particles that girls like to use are polite words, less vulgar than boys, and boys use rougher words [3].

\section{Difference in Grammar Development}

Grammar is a part of linguistics, including the word formation, the rules of word formation and the rules of sentence formation. It is the science of exploring and describing the grammatical structure, and it is the understanding and interpretation of the objective existing grammatical system [11]. There is no difference in grammar itself, but differences in grammar, materials, observation methods and analytical methods lead to grammatical difference. It reflects the various relationships among the
Note: the figure in the cell is the average accuracy, and the figure in bracket is the standard deviation. language units. Sometimes the same words used by boys and girls do not have the same meaning. Boys generally use more direct and decisive language, and girls use more euphemistic and implicit language.

\section{Difference in Pragmatic Development}

The difference in pragmatic development is mainly manifested in the expressing way and expressed content [4].

There is a difference of being "implicit" and "explicit" in the expressing way between boys and girls: the words of girls tend to be "implicit", which are not direct, but implicative and euphemistic and they are rarely directly expressed, while boys speak more directly and decisively.

Boys and girls have difference in what they say to be rough or subtle. The girls are more scrupulous, speaking small details or trivial matters. What the boys said is more general, just an outline.

\section{EFFECTIVE INTERVENTIONS FOR GENDER DIFFERENCE IN THE LANGUAGE DEVELOPMENT OF CHILDREN.}

\section{A. Gender-based Teaching, Giving Different Guidance to Language Learning}

Gender is one of the reasons resulting in the difference in language between boys and girls. Languages are different because of different genders. In life, we can let boys see more picture book stories and fairy tales. They can contact some things that they do not know before through stories and 
common sense. So let's put it together and balance like this, the language expression will not be monotonous. [15]

\section{B. Self-regulated Learning, Giving Full Play to the Advantages of Different Genders}

Let children learn by themselves and find what they are good at to continue to develop. The attentions of girls are more stable and their memory is better, and they have certain abilities of language imitation, so they can develop language learning according to their own advantages, and the thinking abilities of boys are better, so we should communicate with the boys much more and let children know more, which can promote the language learning.

\section{Game Learning, Mobilizing the Enthusiasm of Language Learning}

Monotonous knowledge learning is very boring, so the game is the best way to learn. We can design the knowledge that is suitable for the language development of children in the game, so that it is not very hard for children to learn, and they will not be tired of it, and they can master the knowledge points in the happy game activities. The interesting learning can mobilize the enthusiasm of children to learn language.

\section{Cooperative Learning, Achieving the Complementarity of Gender Difference}

The difference in the language development between boys and girls can let children work together and learn together. In this way, boys will come into contact with the language that girls are interested in. Girls will also come into contact with the language of boys. Children are also better at imitation, so cooperative learning can make children promote each other, make up for each other and learn from each other, which will reduce the language difference resulting from different genders.

\section{CONCLUSION}

This paper puts forward four major strategies for the influence and effect of gender difference factor in the language development of children through searching the relevant literatures of the researches on gender difference in the language development process of children.

- Gender-based teaching, giving different guidance to language learning

- Self-regulated learning, giving full play to the advantages of different genders

- Game learning, mobilizing the enthusiasm of language learning

- Cooperative learning, achieving the complementarity of gender difference

\section{REFERENCES}

[1] Yanqin Xia, Qunxia Zou. Language Education for Pre-School Children [M]. Beijing: Higher Education Press, 2013.

[2] Li Zheng, Yi, Fang Tingting Yao, Jinhuan Yang. Annual Research Report on Language Development and Education of Preschool Children in China from 2011 to 2013 [J].Early Childhood Education, 2015 (36): 3-7.

[3] Wan Zhou. A Summary of the Generalization of Chinese Children's Early Parts of Speech [J]. Data of Culture and Education, 2016 (35): 1921.

[4] Children'S Language Acquisition and Children's General Cognitive Development Law [J]. Xiangfei Guo. Foreign Language Research. 2012 (04). 